\title{
Method Development Combined with in silico Therapeutic and Toxicology Studies on Palbociclib and its Degradation Products to Assist in Discovery of New Molecule
}

\author{
Shaik Reehana*, Kamepalli Sujana \\ Department of Pharmaceutical Analysis, University College of Pharmaceutical Sciences, Acharya Nagarjuna University, Guntur, Andhra Pradesh, INDIA.
}

\begin{abstract}
Background: Palbociclib is anti-cancer drug which interacts with cyclindependent kinase. There are no methods repoRTed for the characterization of palbociclib together with degradation products (DPs). The main aim of the study is to develop method combined with in silico therapeutic and toxicology studies on palbociclib and its DPs which assist in discovery of new molecule. Methods: A new analytical method was developed for the identification, characterization of palbociclib and DPs formed when subjected to forced degradation, using symmetry $C_{18}$ column, $150 \mathrm{~mm} \times 4.6 \mathrm{~mm}$, $3.5 \mu \mathrm{m}$ in isocratic mode with acetonitrile: formic acid $(0.1 \%)(50: 50)$. In silico toxicity for drugs and DPs were predicted using the Swiss ADME web tool and StarDrop Derek Nexus software for all DPs. Results: Validation: LOD and LOQ were 0.01 and $0.1 \mu \mathrm{g} / \mathrm{ml}$. which shows accuracy data at three different concentrations of 50,100 , and $150 \%$ in triplicate analysis. The \% RSD for intra-day and intermediate precision was $0.47 \%$ and $0.33 \%$, respectively, indicating the method was sufficiently precise. Mass spectrums (LC-MS/MS) of drug with $\mathrm{m} / z$ 447(RT= $4.075 \mathrm{~min}$ ), DPI with $[\mathrm{M}+\mathrm{H}]{ }^{+}$at $\mathrm{m} / \mathrm{z} 503(\mathrm{RT}=1.328 \mathrm{~min})$, DPII with $[\mathrm{M}+\mathrm{H}]{ }^{+}$at $\mathrm{m} / z 540$
\end{abstract}

(RT=2.371 $\mathrm{min}$ ), DPIII with $\mathrm{m} / \mathrm{z} 46$ (RT=3.741 $\mathrm{min}$ ) are reported. In docking studies, PS2 showed a higher docking score -12.289. Conclusion: The drug was found to degrade under forced degradation and DPs are characterized. All the DPs were found to be toxic except the major fragment ions (PS2), showed higher binding affinity than drug without toxicity. This is the lead molecule for further drug discovery.

Key words: Forced degradation, LC-MS/MS, Swiss ADME web tool and StarDrop Derek Nexus software, Analytical Method development, Anticancer drug.

\section{Correspondence}

Shaik Reehana

Department Of Pharmaceutical Analysis, University College of Pharmaceutical Sciences, Acharya Nagarjuna University, Nagarjuna Nagar, Guntur-522510, Andhra Pradesh, INDIA.

Email id: reehana28@gmail.com

DOI: 10.5530/ijpi.2021.4.71

\section{INTRODUCTION}

According to International Council on Harmonisation guidelines, ${ }^{1}$ stability testing of pharmaceutical drugs under different stress conditions should be performed because they undergo physic-chemical changes or degradation during the synthesis or upon storage produce process impurities and degradation products (DPs), which ends up in toxicity or side effects. Liquid Chromatography (LC) combined with Tandem mass spectrometry (MS/MS) are available for the identification and characterization of process impurities and DPs. Evaluating activity through molecular docking and toxicity ${ }^{2-11}$ of DPs with the assistance of Computational tools helps in proposing the structures for the DPs, which normally explained by appropriate mechanisms. The molecular docking studies are useful for determining the binding capacity of drug molecules and their DPs towards the corresponding protein. Supported extensive literature search, LC-MS-MS ${ }^{12-19}$ and LC techniques ${ }^{20}$ were reported for therapeutic drug monitoring investigations in humans, animals and Pharmaceutical formulations. Hence, no method reported thus far for the characterization of Palbociclib together with DPs. During this study, we developed a method and validated by High-performance liquid chromatography coupled with electrospray ionization-quadrupole-time of flight-mass spectrometry (LC-ESI-QTOF-MS) method, SwissADME web tool was used for ADME, licensed StarDrop Derek Nexus used for the prediction of toxicological studies and Schrodinger software for Molecular Docking.

\section{MATERIALS AND METHODS}

\section{Chemicals and reagents}

Palbociclib standard was procured from Pharma Train Lab (Hyderabad, India). Acetonitrile and formic acid were purchased from Finar Chemicals (Ahmedabad, India). High performance liquid chromatography (HPLC) grade water. Analytical grade reagents of sodium hydroxide, hydrochloric acid, 30\%hydrogen peroxide, and sodium bisulphate.

\section{Instrumentation}

Liquid chromatography instrument comprised Waters alliance model e2695, a Waters (2998) Photodiode array Detector, a Waters (2700) Auto sample injector, Solvent degasser, Quaternary pump, Temperaturecontrolled compartment. A thermal degradation study was administered employing a hot air oven.

\section{LC conditions}

Chromatographic separation was obtained with isocratic elution using mobile phase 50:50v/v Acetonitrile and formic acid (0.1\%) pumped from a solvent reservoir with a flow rate of $1.0 \mathrm{~mL} / \mathrm{min}$ to the analytical column of the Symmetry $\mathrm{C}_{18}$ column $(150 \times 4.6 \mathrm{~mm}$ i.e., particle size $3.5 \mu \mathrm{m})$ using column back pressure of 1570-1620 at the detector maximum wavelength of $220 \mathrm{~nm}$. Detector performance was evaluated to assess the height peak area and other device suitability parameters using Empower-2 software. The injection volume was used at $0.1 \mathrm{~mL}$ and 
therefore the ambient column temperature was maintained throughout the analysis.

\section{Forced degradation study}

A standard solution of $50 \mu \mathrm{g} / \mathrm{mL}$ was prepared by weighing $5 \mathrm{mg}$ of drug, transferring into $50 \mathrm{ml}$ volumetric flask and diluted with mobile phase (as diluent). The chemical stability and pathway of degradation of any drug substance were determined by performing the stress degradation study in several stress environments as per ICH guidelines. The drug was exposed to hydrolytic degradation (acidic, neutral, and basic), photolytic, oxidative, reduction, and thermal degradation conditions specified in Table 1. Hydrolytic degradation studies were allotted using $1 \mathrm{~N} \mathrm{HCl}$ (acidic) and $1 \mathrm{~N} \mathrm{NaOH}$ (alkaline) and HPLC grade water (neutral) at $70^{\circ} \mathrm{C}$ for twenty-four hours. Oxidative degradation study was performed by using oxide (30\%) at temperature for twenty-four hours and for performing the photolytic degradation, the sample was exposed to sunlight for twenty-four hours. The drug was exposed to $105^{\circ} \mathrm{C}$ for $3 \mathrm{hr}$ in very hot air oven for thermal degradation study. The purity study of drug substances and all degradation products formed were checked using a PDA detector.

\section{MS conditions}

All the DPs generated during study were characterized by using Agilent 1200 array consisting of Q-TOF mass spectrometer. All the experiments were conducted under the positive mode of electron spray ionization (ESI). All the acquisition of statistics was achieved with the use of the software program MassHunter V 5.0. The parameters and conditions maintained for the optimized study explained in Table 2.

\section{In silico Toxicity study}

In silico $\mathrm{ADME}$ and toxicity predictions were performed using the Swiss ADME tool and StarDrop Derek Nexus (Optibrium). The basis of prediction software is the relationship of physicochemical properties such as $\log \mathrm{P}$ and solubility with those of pharmacokinetics of the compound. The tools calculated physicochemical properties and predicted the pharmacological and toxic properties of the degradation products.

Table 1: Forced Degradation studies.

\begin{tabular}{ccccc}
\hline Type of & Stress Conditions & $\begin{array}{c}\text { Degradation } \\
\text { Degradation }\end{array}$ & & \multicolumn{2}{c}{ Peak purity } \\
\cline { 4 - 5 } & & & $\begin{array}{c}\text { Purity } \\
\text { Threshold }\end{array}$ & $\begin{array}{c}\text { Purity } \\
\text { Angle }\end{array}$ \\
\hline $\begin{array}{c}\text { Acidic } \\
\text { hydrolysis } \\
\text { Basic } \\
\text { hydrolysis }\end{array}$ & $\begin{array}{c}1 \mathrm{~N} \mathrm{HCl} \mathrm{at} 70^{\circ} \mathrm{C} \\
\text { for } 24 \mathrm{hr}\end{array}$ & 23.1 & 0.125 & 1.063 \\
$\begin{array}{c}1 \mathrm{NaOH} \text { at } 70^{\circ} \mathrm{C} \\
\text { for } 24 \mathrm{hr}\end{array}$ & 21.1 & 0.129 & 1.034 \\
$\begin{array}{c}30 \% \mathrm{H}_{2} \mathrm{O}_{2} \text { for } 24 \mathrm{hr} \\
\text { Reduction }\end{array}$ & $\begin{array}{c}10 \% \text { sodium } \\
\text { bisulfate }\end{array}$ & 23.7 & 0.168 & 1.069 \\
$\begin{array}{c}\text { Thermal } \\
105^{\circ} \mathrm{C} \text { for } 3 \mathrm{hr}\end{array}$ & - & 0.125 & 1.044 \\
$\begin{array}{c}\text { Neutral } \\
\text { Hydrolysis } \\
\text { Photolytic }\end{array}$ & $\begin{array}{c}\mathrm{H}_{2} \mathrm{O} \text { at } 70^{\circ} \mathrm{C} \\
\text { Sunlight for } 24 \mathrm{hr}\end{array}$ & - & 0.147 & 1.064 \\
\hline
\end{tabular}

Table 2: Chromatographic conditions for optimized method.

\begin{tabular}{|c|c|c|}
\hline \multicolumn{3}{|c|}{ LC Conditions } \\
\hline Stationary phase & $:$ & Symmetry $\mathrm{C}_{18^{\prime}} 150 \mathrm{~mm} \times 4.6 \mathrm{~mm}, 3.5 \mu \mathrm{m}$. \\
\hline Mobile Phase & $:$ & $0.1 \%$ ORThophosphoric acid: acetonitrile \\
\hline Elution mode & $:$ & Isocratic $A: B=50: 50 \% \mathrm{v} / \mathrm{v}$ \\
\hline Flow rate & $:$ & $1.0 \mathrm{ml} / \mathrm{min}$, \\
\hline Sample volume & $:$ & $10 \mu \mathrm{l}$ using Rheodyne $7725 \mathrm{i}$ injector \\
\hline Oven Temperature & $:$ & Ambient \\
\hline \multicolumn{3}{|c|}{ MS Conditions } \\
\hline Interface & $:$ & ESI \\
\hline Operation mode & : & MRM \\
\hline Polarity & $:$ & Positive \\
\hline Capillary voltage & : & $4 \mathrm{KV}$ \\
\hline Fragmentor voltage & $:$ & $170 \mathrm{~V}$ \\
\hline Skimmer voltage & $:$ & $65 \mathrm{~V}$ \\
\hline Nebulizer Gas flow & : & 40 psig \\
\hline Drying gas & : & $10 \mathrm{~L} / \mathrm{min}$ \\
\hline Gasoline temperature & : & $325^{\circ} \mathrm{C}$ \\
\hline Detection & : & $m / z: 0-800$ \\
\hline Data station & $:$ & MassHunter V 5.0 \\
\hline
\end{tabular}

\section{Molecular Docking}

Preparation and grid generation of protein $5 \mathrm{~L} 2 \mathrm{I}$

The protein preparation wizard in the maestro task was selected for protein preparation and energy minimization. The X-ray co-crystal structure of human CDK6 and Palbociclib (PDB code: 5L2I) ${ }^{21}$ was imported into the maestro workspace, it is initially pre-processed all default parameters like assign bond orders, add hydrogens, create zero-order bonds t metals, create disulphide bonds, convert selenomethionines to methionine's

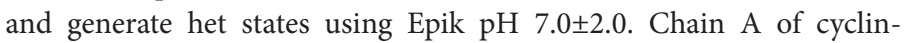
dependent kinase 6 with 307 sequence length and co-crystal ligand LQQ (palbociclib) were selected in the review and modify tab. Water molecules were also deleted, as they were not making any interactions with both ligand and protein. Finally, the protein is optimized by using the OPLS3e force field ${ }^{22}$ by keeping all default settings. The active site or binding site of the co-crystal ligand in the protein was selected for docking of compounds by generating a grid surrounding it. It was done by selecting any atom of the co-crystal palbociclib in the workspace and keeping all default settings, this enables a grid box in protein with $\mathrm{X}, \mathrm{Y}$, and $\mathrm{Z}$ coordinates $13.89,28.25,9.72$ and the $\mathrm{X}, \mathrm{Y}, \mathrm{Z}$ grid dimensions 15 , $15,15 \AA$.

The Ramachandran (RP) plot, PROCHECK, ${ }^{23}$ ERRAT $^{24}$ analysis, VERIFY3D ${ }^{25}$ results were commonly used to indicate the quality of a protein model.

\section{Ligand preparation}

ChemDraw Ultra Version 8.0.3 (Cambridge Soft MA, USA) used to draw the structures of molecules. OpenBabelGUI version 2.4.1 was used to convert ChemDraw binary format .cdx files to .sdf format. The glide Ligprep tool was utilized to prepare ligands for docking studies, all the ligands in .sdf format were imported and subjected to energy minimization by using OPLS3e force field along with all default settings in Ligprep like ionization (possible states at target $\mathrm{pH} 7.0 \pm 2.0$ using Epik), desalt, retain specified chirality's. 
Glide ligand docking standard precision was selected for the docking studies of the ligands. The ligand docking findings were ranked from lowest to highest binding energy based on their interactions with the amino acid residues in the protein's binding pocket.

\section{Validation}

The developed method was validated as per ICH guidelines parameters.

\section{RESULTS}

Different run conditions, columns, and mobile phases were tried for optimizing chromatographic conditions. Different mobile phases like formic acid (in varying percentages from 0.05 to $0.5 \%$ ), Ammonium acetate, and Ammonium format were used for optimizing the conditions. Formic acid at $(0.1 \%)$ and Acetonitrile: $(50: 50 \mathrm{v} / \mathrm{v})$ using Symmetry $\mathrm{C}_{18}$ (150 X4.6mm, $3.5 \mu \mathrm{m})$ showed good peak shape and short retention time with good resolution with no peak tailing. Among different flow rates, $1.0 \mathrm{~mL} / \mathrm{min}$ showed no peak tailing with a short retention time to permit high sample throughput analysis. The RT of Palbociclib is about $3.965 \mathrm{~min}$.

\section{Method of validation}

Good linearity was achieved at concentrations of $0-20 \mu \mathrm{g} / \mathrm{ml}(R 2=0.999)$. Limit of detection (LOD) and limit of quantification LOQ were 0.01 and $0.1 \mu \mathrm{g} / \mathrm{ml}$. (Table 3 ) shows accuracy data at three different concentrations of 50,100, and $150 \%$ in triplicate analysis. The recoveries were found within the range of $99.9 \%$ and $100.3 \%$. The $\%$ RSD for intra-day and intermediate precision was 0.47 percent and 0.33 percent, respectively, indicating that the method was sufficiently precise. Robustness was tested by varying the flow rate and percent of the Organic phase at three distinct concentrations. Each sample was injected three times $(n=3)$, and the mean and \%RSD values were calculated using the peak areas obtained. The $\%$ RSD was $<1$.

\section{Stress decomposition behaviour}

All DPs formed are resolved with drug substance indicating the method is specific. The purity of drug and DPs was less than the purity threshold. There was no interference of any other peak of DP, which ensures the selectivity of the method. Three DPs named as DPI, DP-II and DP-III were formed in hydrolytic (acidic and alkaline), reduction, oxidative stress conditions respectively. The chromatograms obtained for different stress conditions along with control are depicted in (Figure 1) In (Figure 2) all the mass spectrums of the drug and its degradations products are depicted.

\section{MS/MS Palbociclib}

Drug with $\mathrm{m} / \mathrm{z} 447(\mathrm{R} t=4.075 \mathrm{~min})$ displayed the product ions at $\mathrm{m} / \mathrm{z}$ $305, \mathrm{~m} / z 242, \mathrm{~m} / \mathrm{z} 211, \mathrm{~m} / z$ 176. The high abundant product ion observed at $m / z 305$ due to the loss of $\mathrm{C}_{5} \mathrm{H}_{10}, \mathrm{C}_{2} \mathrm{H}_{4} \mathrm{O}, \mathrm{H}_{2} \mathrm{O}$, and other fragment ions of $m / z 242$ due to the loss of $\mathrm{C}_{4} \mathrm{H}_{11} \mathrm{~N}$ from the ion, $\mathrm{m} / z 211$ due to the loss of $\mathrm{C}_{2} \mathrm{H}_{7} \mathrm{~N}$ and $\mathrm{m} / z 176$ due to the loss of $\mathrm{C}_{3} \mathrm{H}_{8}$.

\section{MS/MS DPI}

DPI with $[\mathrm{M}+\mathrm{H}]^{+}$at $\mathrm{m} / z 503(\mathrm{RT}=1.328 \mathrm{~min})$, was formed under hydrolytic stress conditions. The DPI showed distinctive product ions at $m / z 433,417,333,347,323,253$, and 153 . The product ions of $m / z$ 433 (loss of $\mathrm{C}_{5} \mathrm{H}_{10}$ from the parent ion at $\mathrm{m} / z 503$ ), $\mathrm{m} / z 417$ (loss of $\mathrm{C}_{4} \mathrm{H}_{10} \mathrm{~N}_{2}$ from the parent ion at $\mathrm{m} / z 503$ ), $m / z 333$ (loss of $\mathrm{C}_{7} \mathrm{H}_{14} \mathrm{O}$ from the fragment ion at $\mathrm{m} / z 433$ ), $\mathrm{m} / z 347$ (loss of $\mathrm{C}_{5} \mathrm{H}_{10}$ from the ion at $\mathrm{m} / z$ 417), $\mathrm{m} / z 323$ (loss of $\mathrm{C}_{5} \mathrm{H}_{6} \mathrm{~N}_{2}$ from the ion at $\mathrm{m} / z$ 417), $\mathrm{m} / z 253$ (loss of $\mathrm{C}_{5} \mathrm{H}_{10}$ from the ion at $m / z 323$ ), $m / z 153$ ( loss of $\mathrm{C}_{7} \mathrm{H}_{14} \mathrm{O}$ from the ion at $m / z 253$ ).

\section{MS/MS DPII}

DPII with $[\mathrm{M}+\mathrm{H}]^{+}$at $\mathrm{m} / \mathrm{z} 540(\mathrm{RT}=2.371 \mathrm{~min})$, was formed under hydrolytic stress conditions. The DPII showed distinctive product ions at $\mathrm{m} / \mathrm{z} 470,439,369,352,283,258$, and 188 . The product ions of $m / z$ 470 (loss of $\mathrm{C}_{5} \mathrm{H}_{10}$ from the parent ion at $\mathrm{m} / z 540$ ), $\mathrm{m} / \mathrm{z} 439$ (loss of $\mathrm{C}_{5} \mathrm{H}_{10} \mathrm{O}_{2}$ from the parent ion at $\mathrm{m} / \mathrm{z} 540$ ), $\mathrm{m} / \mathrm{z} 369$ (loss of $\mathrm{C}_{5} \mathrm{H}_{10}$ from the fragment ion at $m / z 438$ ), $\mathrm{m} / \mathrm{z} 352$ (loss of $\mathrm{C}_{4} \mathrm{H}_{10} \mathrm{~N}_{2}$ from the ion at $\mathrm{m} / z$

Table 3: Summary of Validation.

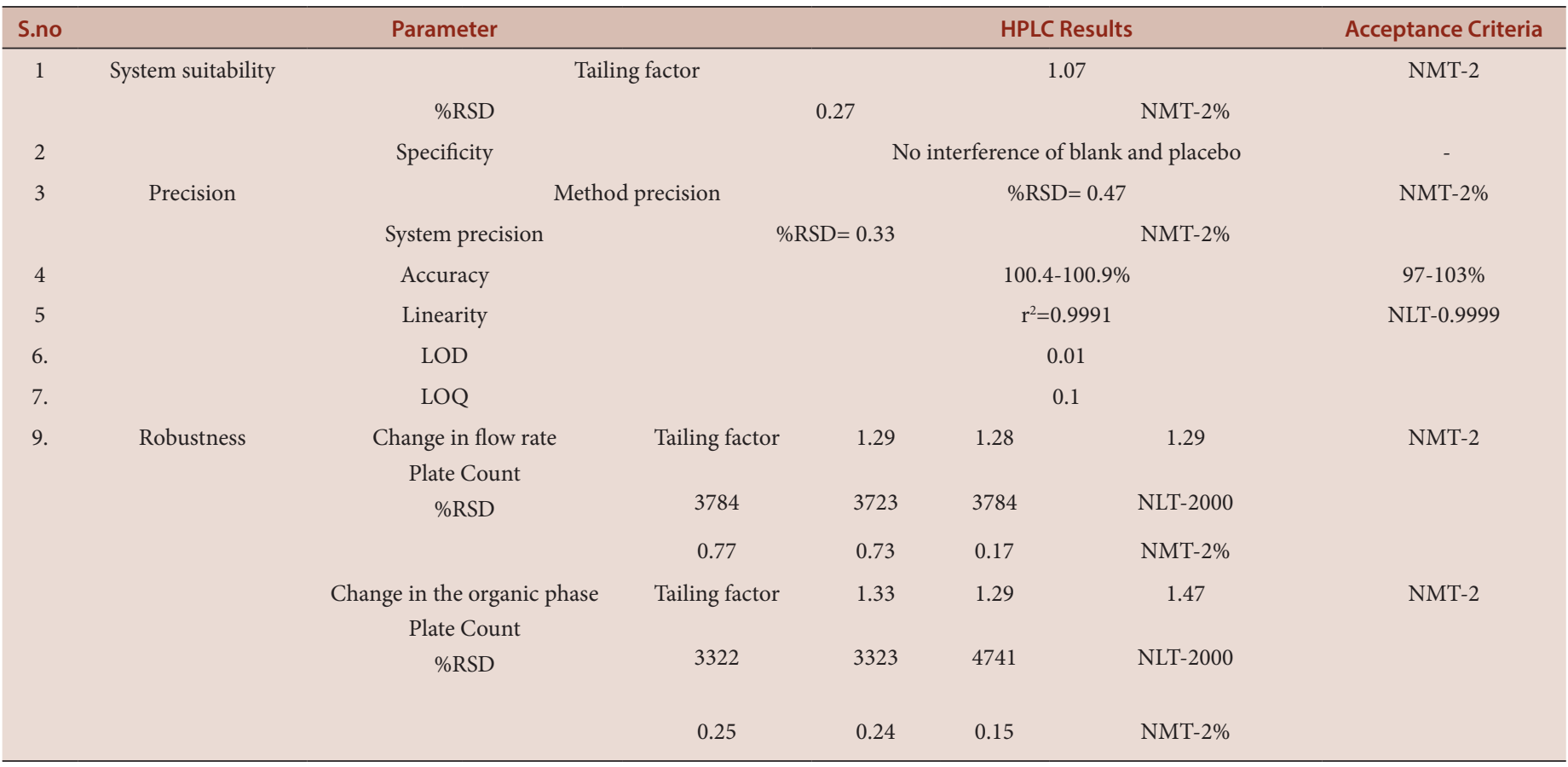




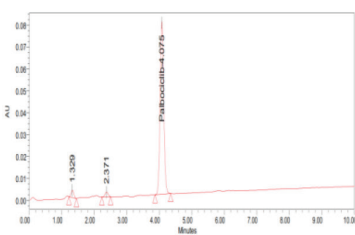

Chromatogram for Acid Degradation

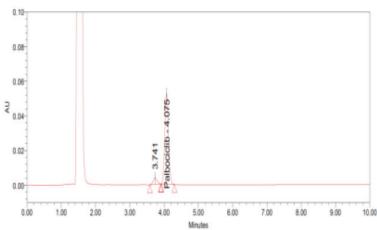

Chromatogram for Peroxide Degradation

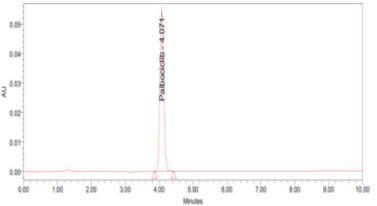

Chromatogram for Degradation by Hydrolysis

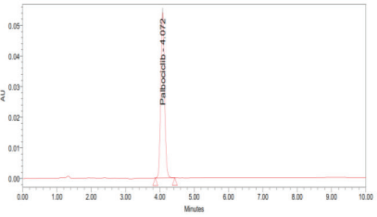

Chromatogram for Degradation by thermal

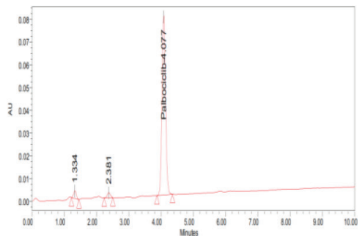

Chromatogram for Base Degradation

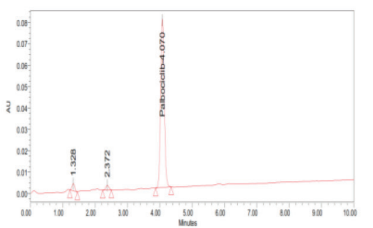

Chromatogram for Degradation by Reduction

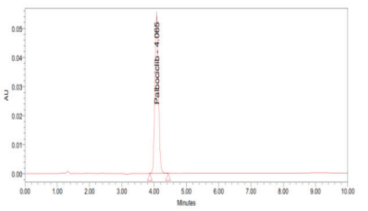

Chromatogram for Degradation by Photolysis

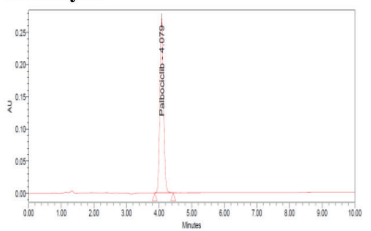

Chromatogram for Control

Figure 1: Representative Chromatograms for forced degradation conditions.

438), $m / z 283$ (loss of $\mathrm{C}_{4} \mathrm{H}_{10} \mathrm{~N}_{2}$ from the ion at $\mathrm{m} / z$ 369), $\mathrm{m} / z 258$ (loss of $\mathrm{C}_{5} \mathrm{H}_{6} \mathrm{~N}_{2}$ from the ion at $\mathrm{m} / z$ 352), $\mathrm{m} / z 188$ (loss of $\mathrm{C}_{5} \mathrm{H}_{6} \mathrm{~N}_{2}$ from the ion at $m / z 283$ ).

\section{MS/MS DPIII}

DPIII with $m / z 463$ ( $\mathrm{t} t=3.741 \mathrm{~min}$ ) was formed under oxidative stress conditions. The product ions of $m / z 393$ (loss of $\mathrm{C}_{5} \mathrm{H}_{10}$ from the parent ion at $m / z 463$ ), $m / z 377$ (loss of $\mathrm{C}_{4} \mathrm{H}_{10} \mathrm{~N}_{2}$ from the parent ion at $m / z$ 463 ), $m / z 349$ (loss of $\mathrm{C}_{2} \mathrm{H}_{4} \mathrm{O}$ from the fragment ion at $m / z 393$ ), $m / z 307$ (loss of $\mathrm{C}_{4} \mathrm{H}_{10} \mathrm{~N}_{2}$ from the ion at $\mathrm{m} / z 393$ ), $\mathrm{m} / z 263$ (loss of $\mathrm{C}_{4} \mathrm{H}_{10} \mathrm{~N}_{2}$ from the ion at $m / z 349$ ), $m / z 197$ (loss of $\mathrm{C}_{5} \mathrm{H}_{11} \mathrm{~N}_{2} \mathrm{O}$ from the ion at $\mathrm{m} / z$ 307), $m / z 153$ ( loss of $\mathrm{C}_{5} \mathrm{H}_{11} \mathrm{~N}_{2} \mathrm{O}$ from the ion at $m / z 263$ ). All the schemes for proposed fragmentation pathways for degradation products depicted in (Figure 3).

Using Lipinski, the in silico techniques predicted drug breakdown products (Table 4). The GI absorption for drugs and their degradation products is high and may cause adverse effects by entering the bloodstream through the gastrointestinal tract. The capability to penetrate the blood-brain barrier (BBB) for drugs and their degradation products has significantly higher scores for this phenomenon. All the DPs show less toxicity because of the low $\log \mathrm{kp}$ value than drug. The toxicity screening for the drug and DPs were performed and the results were elaborated in (Table 5). In the present research, all three degradation products were found to be toxic. Hence fragment ions obtained from degradation products which are non-toxic were screened for molecular docking. Total seven fragment ions are nontoxic which are named as PS1, PS2, PS3, PS4, PS5, PS6, and PS7. The docking results (Table 6, Figure 4), reveals that the co-crystal ligand Palbociclib showed hydrogen bond interactions with
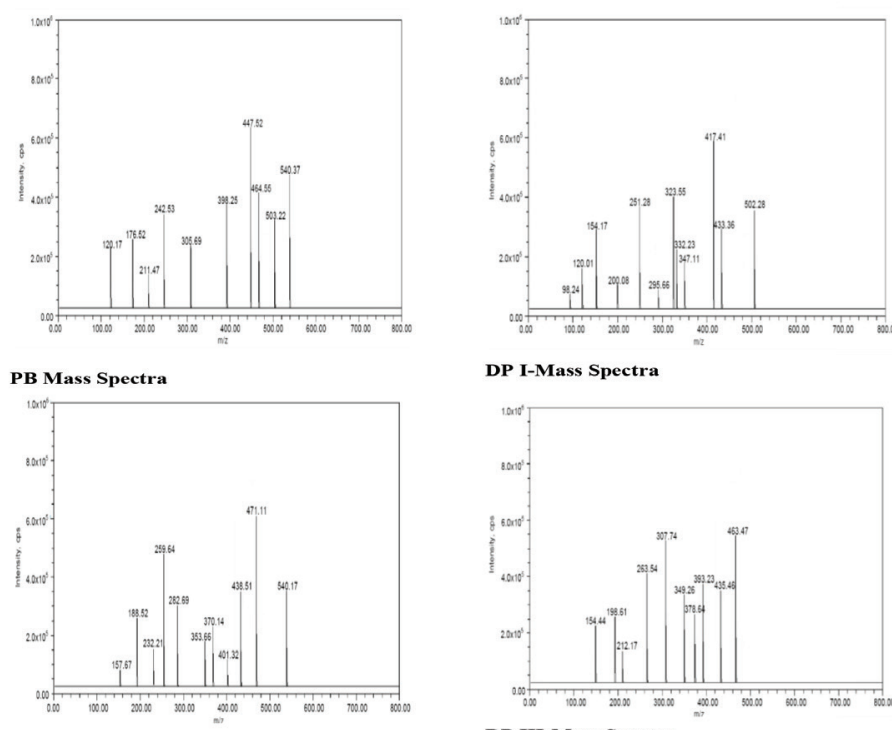

DP II-Mass Spectra

DP I-Mass Spectra

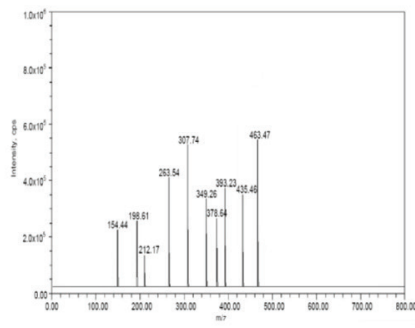

DP III-Mass Spectra

Figure 2: Representative MS/MS Spectra for Drug and Degradation products.
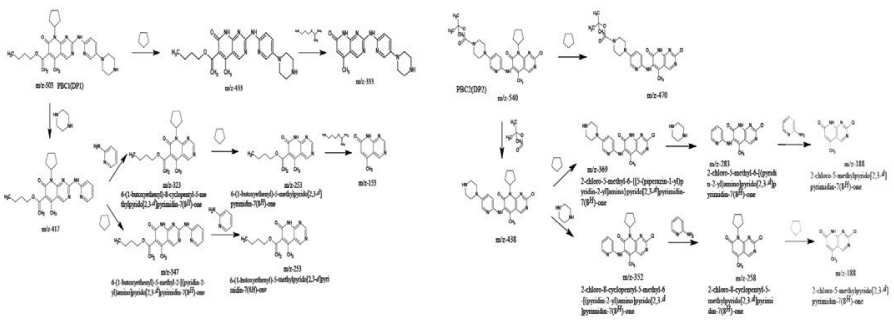

Scheme for Degradation Pathway for DP1

Scheme for Degradation Pathway for DP2
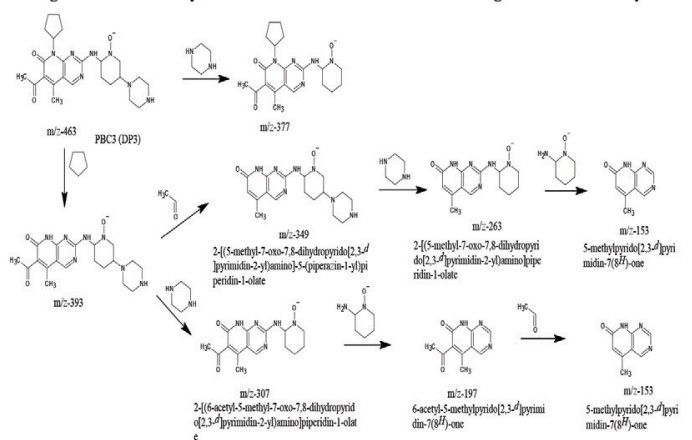

Scheme for Degradation Pathway for DP3

Figure 3: Schemes for proposed degradation pathway.

the amino acid residues VAL 101 and ASP 163 with a docking score of -11.571. Most of the all compounds PS1 to PS7 exhibited an identical type of interactions in the binding pocket, among all compounds, PS2 showed a higher docking score -12.289 than the standard Palbociclib without toxicity.

\section{DISCUSSION}

The mobile phase formic acid at $(0.1 \%)$ : acetonitrile $(50: 50 \mathrm{v} / \mathrm{v})$ ratio was used in the HPLC procedure with a Symmetry $C_{18}(150$ $\mathrm{X} 4.6 \mathrm{~mm}, 3.5 \mathrm{~m}$ ) column with $220 \mathrm{~nm}$ PDA detection under optimum chromatographic conditions. The optimal flow rate was determined to 
Table 4: ADME studies by using the SWISS tool.

\begin{tabular}{|c|c|c|c|c|c|c|c|c|c|}
\hline \multirow[t]{2}{*}{ Drug } & \multirow[t]{2}{*}{ BBB Permeation } & \multirow[t]{2}{*}{ GI Absorption } & \multicolumn{5}{|c|}{ CYP Inhibition } & \multirow[t]{2}{*}{$\log K p$} & \multirow{2}{*}{$\begin{array}{c}\text { Lipinski } \\
\text { Violation }\end{array}$} \\
\hline & & & $1 \mathrm{~A} 2$ & $2 C 19$ & $2 C 9$ & 2D6 & $3 \mathrm{~A} 4$ & & \\
\hline Palbociclib & High & High & No & No & No & Yes & No & -8.33 & 0 \\
\hline DP1 & High & High & No & Yes & Yes & Yes & Yes & -6.7 & 1 \\
\hline DP2 & High & High & No & Yes & Yes & Yes & Yes & -6.73 & 1 \\
\hline DP3 & High & High & No & No & Yes & Yes & Yes & -7.74 & 0 \\
\hline
\end{tabular}

Table 5: Toxicological profile of the compounds using Star Drop Nexus.

\begin{tabular}{|c|c|c|c|c|}
\hline $\begin{array}{l}\text { Drug/ Degradation } \\
\text { product }\end{array}$ & $\mathrm{m} / \mathrm{z}$ & Toxicity & Structure & $\begin{array}{l}\text { Group responsible } \\
\text { for toxicity }\end{array}$ \\
\hline Palbociclib & 447.52 & Phospholipidosis & & 1-(pyridin-3-yl)piperazine \\
\hline DP1 & 503 & Phospholipidosis & & 1-(pyridin-3-yl)piperazine \\
\hline \multirow[t]{2}{*}{ DP2 } & 540 & Hepatotoxicity & & carbamimidyl chloride \\
\hline & & Respiratory sensitization & & 2-chloropyrimidine \\
\hline \multirow[t]{2}{*}{ DP3 } & 463 & HERG channel inhibition & & $\begin{array}{c}\text { 2-carbamimidamido-5-(dimethylamino) } \\
\text { piperidin-1-olate }\end{array}$ \\
\hline & & Skin sensitization & & 1-methyl piperazine \\
\hline
\end{tabular}

be $1 \mathrm{~mL} / \mathrm{min}$. Palbociclib was isolated with improved sensitivity and excellent peak shape in $3.965 \mathrm{~min}$. The linearity analysis for the HPLC technique yielded a regression coefficient value of 0.999 , showing that the method is linear. The percentage of RSD for the precision analysis utilising the HPLC procedure was less than2, indicating that the HPLC methods developed were accurate. The average percentage recovery results for the HPLC technique of 100.4-100.9 percent demonstrated the accuracy of the methods produced because the values were within the acceptability limit. According to the findings of the LOD and LOQ tests, method established for palbociclib were shown to be sensitive and easily measurable. The robustness analysis results reveal that there are no significant changes in the outcome of slight deliberate adjustments in the mobile phase ratio and mobile phase flow rate, indicating that the approach method is resilient.

The drug found to be more vulnerable to acid, alkali, reduction, and peroxide degradation conditions, degrading by $23.1 \%, 21.1 \%, 22.6 \%$, and 
Table 6: Docking score and interactions of compounds with 5L2I protein using Schrodinger.

\begin{tabular}{|c|c|c|c|c|c|}
\hline Code & $\begin{array}{l}\text { Major fragment ions } \\
\qquad \mathrm{m} / \mathrm{z}\end{array}$ & Chemical structure & Chemical formula & Docking score & $\begin{array}{l}\text { Hydrogen bond } \\
\text { interactions }\end{array}$ \\
\hline PS2 & 417 & & $\mathrm{C}_{24} \mathrm{H}_{29} \mathrm{~N}_{5} \mathrm{O}_{2}$ & -12.289 & VAL 101 \\
\hline Palbociclib & 447 & & $\mathrm{C}_{24} \mathrm{H}_{29} \mathrm{~N}_{7} \mathrm{O}_{2}$ & -11.571 & VAL 101, ASP 163 \\
\hline PS3 & 333 & & $\mathrm{C}_{19} \mathrm{H}_{21} \mathrm{~N}_{5} \mathrm{O}_{2}$ & -10.746 & VAL 101 \\
\hline PS1 & 433 & & $\mathrm{C}_{23} \mathrm{H}_{29} \mathrm{~N}_{7} \mathrm{O}_{2}$ & -10.151 & VAL 101, ASP 163 \\
\hline PS1 & 263 & & $\mathrm{C}_{13} \mathrm{H}_{16} \mathrm{~N}_{5} \mathrm{O}_{2}$ & -9.843 & VAL 101 \\
\hline PS5 & 323 & & $\mathrm{C}_{19} \mathrm{H}_{25} \mathrm{~N}_{3} \mathrm{O}_{2}$ & -9.428 & VAL 101, ASP 163 \\
\hline PS7 & 153 & & $\mathrm{C}_{8} \mathrm{H}_{7} \mathrm{~N}_{3} \mathrm{O}$ & -7.937 & GLU 99, VAL 101 \\
\hline PS4 & 253 & & $\mathrm{C}_{14} \mathrm{H}_{17} \mathrm{~N}_{3} \mathrm{O}_{2}$ & -7.152 & VAL 101 \\
\hline
\end{tabular}

$23.7 \%$ respectively. Palbociclib was found to be stable when subjected to neutral hydrolysis, photolysis, and heat deterioration.

The DP-I and DP-II were created under acidic, basic, and reduction conditions, respectively, while the DP-III was formed under oxidative circumstances. All of the DPs were resolved using LC-MS/MS analysis. Palbociclib and DPs degradation pathways and mechanisms have been identified. Palbociclib and DPs degradation pathways and mechanisms have been identified. The Swiss ADME tool was used to determine the in silico Pharmacokinetics. The medication and its degradation products are absorbed in the GI tract and penetrate the blood-brain barrier. This is an orally accessible medicine, and it must have a high GI absorption rate in order to have a high bioavailability. It is not necessary to cross the $\mathrm{BBB}$ because it is primarily used to treat breast cancer. The toxicity of the medication and its degradants was predicted using a Star Drop Derek nexus model, and the results led to some interesting conclusions. The drug and DP1 were predicted to exhibit minor phospholipidosis toxicity due to the presence of the 1-(pyridin-3-yl) piperazine group. DPII causes hepatotoxicity and respiratory sensitization because to the presence of carbamimidyl chloride and 2-chloropyrimidine groups. DPIII inhibits HERG channels, causes skin sensitization, and the hazardous groups are 2-carbamimid amido-5-(dimethyl amino) piperidin-1-olate and 1-methyl piperazine. Glide (Schrodinger) molecular docking was used to determine binding affinities, and PS2 was identified as a fragment ion with a binding affinity greater than palbociclib. The binding affinities for the remaining fragment ions were discovered to be lower. Thus, one fragment ion was discovered to exhibit an intriguing binding affinity for the 5L2I protein, indicating that they may be bioactive in in-vivo experiments. As a result, PS2 has a good probability of being an effective anticancer agent. These experiments yielded several intriguing results, which may be useful in bridging pharmaceutical drug analysis and drug discovery.

\section{CONCLUSION}

The study's goal is not only to investigate the forced degradation products produced under stress conditions utilising LC/MS-ESI-QTOF analysis, but also to perform a comparative in silico toxicological evaluation. In this study, degradation products were studied using in silico techniques and the developed method was precise, linear, accurate, highly sensitive, and dependable, with validation findings that were within the limitations. The developed method was compatible with hyphenated techniques of analysis. Palbociclib degradation routes were investigated under various 


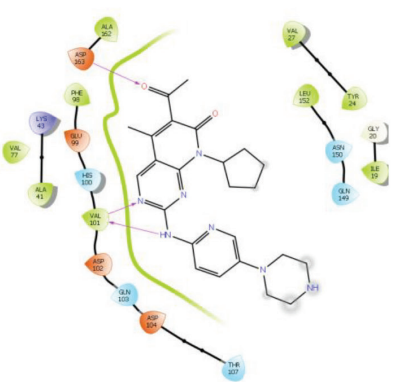

VAL 101, ASP 163 Hydrogen bond interactions of Palbociclib

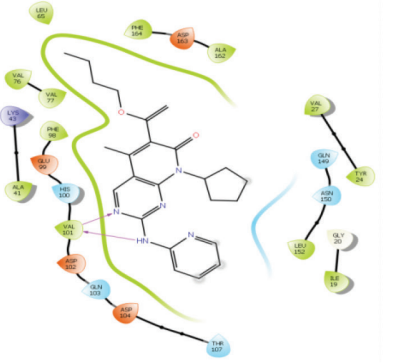

VAL 101 Hydrogen bond interactions of PS2

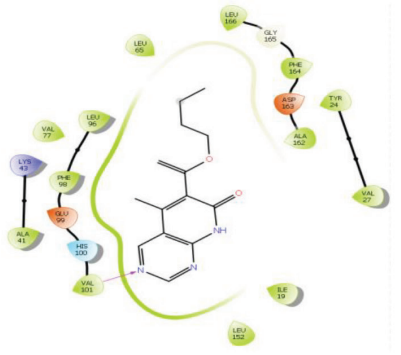

VAL 101 Hydrogen bond interactions of PS4

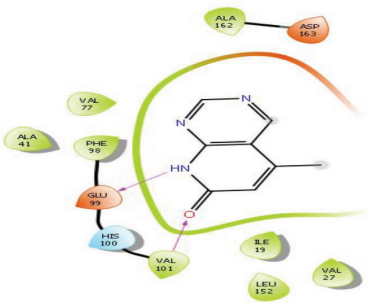

GLU 99, VAL 101 Hydrogen bond interactions with PS6

Figure 4: 2D interactions of compounds with $5 \mathrm{~L} 2 \mathrm{l}$ protein.

forced degradation stress conditions in accordance with ICH criteria. Palbociclib was used to forcefully degrade certain stressful conditions. It is a quick and sensitive HPLC approach capable of isolating Palbociclib and its three degradation products down to the nanogram level and there is a scope for the discovery of new molecules during anticancer therapy.

\section{ACKNOWLEDGEMENT}

The authors are thankful to the Principal, University College of Pharmaceutical Sciences, Acharya Nagarjuna University, Andhra Pradesh, and also RERDS-CPR of Raghavendra Institute of Pharmaceutical Education and Research for providing SCHRODINGER Glide software version 2020_1, the ADMET studies by Swiss ADME and StarDrop Derek Nexus version 6.5.

\section{CONFLICT OF INTEREST}

The authors declare that there is no conflict of interest.

\section{REFERENCES}

1. Guideline $\mathrm{IH}$. Impurities in new drug substances $\mathrm{Q} 3 \mathrm{~A}(\mathrm{R} 2)$. In: Proceedings of the international conference on harmonization of technical requirements for registration of pharmaceuticals for human use, Geneva, Switzerland 2006;25.

2. Lipinski CA, Lombardo F, Dominy BW, Feeney PJ. Experimental and computational approaches to estimate solubility and permeability in drug discovery and development settings. Adv Drug Deliv Rev. 2001;46(1-3):3-26. doi: 10.1016/ s0169-409x(00)00129-0. PMID 11259830.

3. Ekins S, Mestres J, Testa B. In silico pharmacology for drug discovery: Methods for virtual ligand screening and profiling. Br J Pharmacol. 2007:152(1):9-20. doi: 10.1038/sj.bjp.0707305, PMID 17549047.

4. Johnston C, Hilmer SN, McLachlan AJ, Matthews ST, Carroll PR, Kirkpatrick CM. The impact of frailty on pharmacokinetics in older people: Using gentamicin population pharmacokinetic modeling to investigate changes in renal drug clearance by glomerular filtration. Eur J Clin Pharmacol. 2014;70(5):549-55. doi: 10.1007/s00228-014-1652-7, PMID 24522409.

5. Dounay AB, Anderson M, Bechle BM, Evrard E, Gan X, Kim JY, et al. PF-04859989 as a template for structure-based drug design: identification of new pyrazole series of irreversible KAT II inhibitors with improved lipophilic efficiency. Bioorg Med Chem Lett. 2013;23(7):1961-6. doi: 10.1016/j.bmcl. 2013.02.039, PMID 23466229.

6. Durham SK, Pearl GM. Computational methods to predict drug safety liabilities Curr Opin Drug Discov Devel. 2001;4(1):110-5. PMID 11727316.

7. Nigsch F, Macaluso NJ, Mitchell JB, Zmuidinavicius D. Computational toxicology: an overview of the sources of data and of modelling methods. Expert Opin Drug Metab Toxicol. 2009;5(1):1-14. doi: 10.1517/17425250802660467, PMID 19236225.

8. Mosier PD. Prediction of chemical properties and biological activities of organic compounds from molecular structure and use of probabilistic and generalized regression neural networks. Pennsylvania State University; 2003.

9. Snyder RD. An update on the genotoxicity and carcinogenicity of marketed pharmaceuticals with reference to in silico predictivity. Environ Mol Mutagen. 2009;50(6):435-50. doi: 10.1002/em.20485, PMID 19334052

10. $\mathrm{Yu} \mathrm{H}$, Adedoyin A. ADME-Tox in drug discovery: Integration of experimental and computational technologies. Drug Discov Today. 2003;8(18):852-61. doi: 10.1016/s1359-6446(03)02828-9, PMID 12963322

11. Dearden JC. In silico prediction of drug toxicity. J Comput Aid Mol Des. 2003;17(2-4):119-27. doi: 10.1023/a:1025361621494, PMID 13677480

12. Llopis B, Robidou P, Tissot N, Pinna B, Gougis P, Aubart FC, et al. Development and clinical validation of a simple and fast UPLC-ESI-MS/MS method for simultaneous quantification of nine kinase inhibitors and two antiandrogen drugs in human plasma: interest for their therapeutic drug monitoring. J Pharm Biomed Anal. 2021;197(197):113968. doi: 10.1016/j.jpba.2021.113968.

13. Jolibois J, Schmitt A, Royer B. A simple and fast LC-MS/MS method for the routine measurement of cabozantinib, olaparib, palbociclib, pazopanib, sorafenib, sunitinib and its main active metabolite in human plasma. J Chromatogr B Analyt Technol Biomed Life Sci. 2019;1132:121844. doi: 10.1016/j. jchromb.2019.121844

14. Posocco B, Buzzo M, Poetto AS, Orleni M, Gagno S, Zanchetta M, et al. Simultaneous quantification of palbociclib, ribociclib and letrozole in human plasma by a new LC-MS/MS method for clinical application. PLOS ONE. 2020;15(2):e0228822. doi: 10.1371/journal.pone.0228822, PMID 32032379.

15. Al-Shehri M, Hefnawy M, Abuelizz H, Alzamil A, Mohammed M, Alsaif N, et al. Development and validation of an UHPLC-MS/MS method for simultaneous determination of palbociclib, letrozole and its metabolite carbinol in rat plasma and pharmacokinetic study application. Arab J Chem. 2020;13(2):4024-34. doi: 10.1016/j.arabjc.2019.05.005.

16. Leenhardt F, Gracia M, Perrin C, Muracciole-Bich C, Marion B, Roques C, et al. Liquid chromatography-tandem mass spectrometric assay for the quantification of CDK4/6 inhibitors in human plasma in a clinical context of drug-drug interaction. J Pharm Biomed Anal. 2020;188:113438. doi: 10.1016/j.jpba.2020.113438.

17. Martinez-Chávez $A$, Rosing $H$, Hillebrand M, Tibben M, Schinkel AH, Beijnen $\mathrm{JH}$. Development and validation of a bioanalytical method for the quantification of the CDK4/6 inhibitors abemaciclib, palbociclib, and ribociclib in human and mouse matrices using liquid chromatography-tandem mass spectrometry. Anal Bioanal Chem. 2019 Aug:411(20):5331-45. doi: 10.1007/s00216-019-01932-w, PMID 31209549.

18. Paul D, Surendran S, Chandrakala P, Satheeshkumar N. An assessment of the impact of green tea extract on palbociclib pharmacokinetics using a validated UHPLC-QTOF-MS method. Biomed Chromatogr. 2019;33(4):e4469. doi: 10.1002/bmc.4469, PMID 30549069.

19. Chavan BB, Tiwari S, G S, Nimbalkar RD, Garg P, R S, Talluri MVNK. In vitro and in vivo metabolic investigation of the Palbociclib by UHPLC- Q-TOF/MS/MS and in silico toxicity studies of its metabolites. J Pharm Biomed Anal. 2018:157:59-74. doi: 10.1016/j.jpba.2018.05.008, PMID 29772457. 
20. Panda SS, Bera RKVV, Sahu B. Chemometrics supported optimization of a multi-attribute monitoring liquid chromatographic method for estimation of palbociclib in its dosage form: application to a new regulatory paradigm. Ann Pharm Fr. 2021 Mar 1;79(2):125-41. doi: 10.1016/j.pharma.2020.08.006, PMID 32860759 (Vol. 79, No. 2, pp. 125-141). Elsevier Masson.

21. Chen P, Ferre RA, Deihl W, Yu X, HE Y-A. 5L2I The X-ray co-crystal structure of human CDK6 and Palbociclib, RCSB. Protein data bank; 2016.

22. Harder E, Damm W, Maple J, Wu C, Reboul M, Xiang JY, et al. OPLS3: A force field providing broad coverage of drug-like small molecules and proteins. J Chem Theory Comput. 2016;12(1):281-96. doi: 10.1021/acs.jctc.5b00864, PMID
26584231.

23. Kanwal S, Perveen S. In-silico and Molecular Analysis of Reticulon 4asNovel therapeutic option for axonal regeneration. J Pak Med Assoc. 2019;69(10):1425-30. PMID 31622291.

24. Colovos C, Yeates TO. Verification of protein structures: patterns of nonbonded atomic interactions. Protein Sci. 1993;2(9):1511-9. doi: 10.1002/pro.5560020916 PMID 8401235

25. Charan PS, Narad P. In silico analysis and docking studies of semenogelin Targeting Senile Seminal Vesicle Amyloidosis (ssva). Wjpmr. 2017;3(8):182-6.

Article History: Submission Date : 17-08-2021; Revised Date : 20-09-2021; Acceptance Date : 24-10-2021.

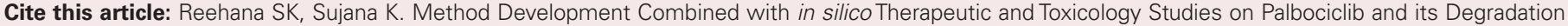
Products to Assist in Discovery of New Molecule. Int. J. Pharm. Investigation. 2021;11(4):395-402. 